American Journal of Animal and Veterinary Sciences 6 (3): 105-111, 2011

ISSN 1557-4555

(C) 2011 Science Publications

\title{
Effect of Dietary Polydextrose on Feces Consistency and Macronutrient Digestibility in Healthy Dogs
}

\author{
${ }^{1}$ K. Vasupen, ${ }^{1}$ C. Yuangklang, ${ }^{1}$ A.C. Beynen and ${ }^{2}$ A.W.C Einerhand \\ ${ }^{1}$ Department of Animal Science, Faculty of Natural Resources, \\ Rajamangala University of Technology Isan, Phang Khon, Sakon Nakhon, Thailand \\ ${ }^{2}$ Tate and Lyle, Innovation Centre, Villeneuve d'Ascq, France
}

\begin{abstract}
Problem statement: There is evidence that the addition of 3\% STA-LITE ${ }^{\circledR}$ polydextrose to a dry food reduces clinical signs of osteoarthritis in dogs. For the application of polydextrose as functional ingredient of dog foods, information as to its impact on the acceptance of food, feces consistency, fecal odor and digestibility of macronutrients and minerals is required. Approach: A feeding experiment with $4 \times 4$ Latin square design was carried out with 12 adult, healthy Golden Retrievers. The experimental diets consisted of a commercial dry food to which either $0,2,4$ or $8 \%$ polydextrose was added. During the last 5 days of each two-week feeding period, feces of individual dogs were collected quantitatively. Feces consistency and fecal odor were scored. Fecal pH, fecal Lactobacilli and the apparent digestibility of macronutrients and minerals were determined. Results: The various inclusion levels of polydextrose did not affect food acceptance and intake and did not induce changes in body weight. Polydextrose intake did not influence fecal odor and the amount of feces production. Feces consistency was significantly affected by polydextrose; feces became softer with increasing dose. The apparent digestibilities of dietary dry matter, crude protein, crude fat and ash were not significantly affected by polydextrose intake. The apparent digestibilities of crude fiber and nitrogen-free extract were increased by the addition of polydextrose to the diet. Apparent digestibility of polydextrose was calculated to be $92 \%$ of intake. The high apparent digestibility of polydextrose points at fermentation of this functional ingredient in the hindgut of dogs, but it was not associated with a further lowering of fecal $\mathrm{pH}$ and increase in fecal Lactobacilli. Apparent calcium and phosphorus absorption were not significantly affected by polydextrose intake. Conclusion: In the clinical trial on canine osteoarthritis, a polydextrose dose of $3 \%$ in a dry dog food is used. The outcome of this study with healthy dogs indicates that $3 \%$ polydextrose may not have negative effects on the variables that are measured.
\end{abstract}

Key words: Polydextrose, food acceptance, feces consistency, macronutrient digestion, calcium absorption, phosphorus absorption

\section{INTRODUCTION}

In a double-blind, placebo-controlled trial we have obtained evidence for a beneficial effect of dietary STA-LITE $^{\circledR}$ polydextrose on the clinical signs of osteoarthritis in dogs (Beynen et al., 2011). The symptoms of osteoarthritis are chronic pain, lameness and decreased mobility which is explained by loss of cartilage matrix and synovitis (Henrotin et al., 2005). On the basis of literature data (Fava et al., 2007; Peuranen et al., 2004), we have suggested that the ingestion of polydextrose fiber mediates an antiinflammatory effect, leading to improvement of osteoarthritis in dogs (Beynen et al., 2011). Polydextrose has an inhibitory effect on cyclo- oxygenase-2 (Makivuokko et al., 2005; Fava et al., 2007). This effect may lead to reduced production of prostaglandin E2 (PG-E2) which is responsible for the clinical signs like pain and swelling of joints.

The evidence that consumption of polydextrose elicits anti-inflammatory activity (Fava et al., 2007; Peuranen et al., 2004) and the observed beneficial effect on canine osteoarthritis (Beynen et al., 2011) could be a basis for the application of polydextrose in petfoods. Polydextrose may be added to dog foods with claims on preventing and/or treating the condition of osteoarthritis. Other inflammatory conditions such as canine atopy, enteritis and colitis might also benefit from the ingestion of polydextrose.

Corresponding Author: C. Yuangklang, Department of Animal Science, Faculty of Natural Resources, Rajamangala University of Technology Isan, Sakon Nakhon, Thailand 
In the clinical trial on canine osteoarthritis, a dry dog food containing $3 \%$ polydextrose was used as test diet (Beynen et al., 2011). Prior to the application of polydextrose in dog foods, it is relevant to assess the effects of polydextrose, if any, on the acceptance of food, food intake, body weight, feces consistency, fecal odor, fecal bacteria and apparent digestibility of macronutrients and minerals. Knowledge of the influence of polydextrose on these variables not only is important for the appropriate use of this functional ingredient in petfoods, but it could also point at additional beneficial effects. In the present doseresponse study with healthy dogs, the variables mentioned were measured.

\section{MATERIALS AND METHODS}

Experimental design: For the experiment, we used 12 adult, healthy Golden Retrievers. There were 8 males and 4 spayed females. The dogs were aged three years. They were housed as a group in an area $(12 \times 12 \mathrm{~m})$ with wire-mesh fence which was located in a building with roof. The sides of the building were open, but when necessary a curtain was used to block sunlight. Within the $\operatorname{dog}$ area there were 12 cages with wire-mesh bottom. The dogs were trained to eat a fixed amount of commercial dry food during a restricted period of 30 $\mathrm{min}$ in the morning and in the late afternoon. During the 30-min periods, each dog had access to its food while locked up in its own cage $(1.90 \times 0.65 \times 0.90 \mathrm{~m})$. Apart from the feeding interval, the dogs could move freely within the area. Tap water was continuously available.

The experiment had a $4 \times 4$ Latin square design: there were four experimental diets, four feeding periods of two weeks each and three dogs per sequence of diets. During the experiment, each dog was fed an amount of food that was equivalent to its habitual daily intake of energy. The diets were administered in the form of two identical meals per day. The dogs had free access to demineralized water.

To calculate the energy value of the habitual diet and of the experimental diets, the energy values for protein, fat and carbohydrates were taken to be 17, 37 and $16 \mathrm{~kJ}$ metabolizable energy per g. The energy content of STA-LITE® polydextrose (Tate and Lyle, France), was set at $4 \mathrm{~kJ}$ per g (Auerbach et al., 2007). The control diet without polydextrose was an extruded commercial dry food (Bok Dök, Nutrix Company Ltd, Muang, Chachoengsao, Thailand). The ingredient list on the packaging was as follows: meat and bone, poultry meal, corn gluten meal, yellow corn, tapioca, wheat bran, vegetable oil, salt, vitamins and minerals and preservatives with vitamin E (tocopheryl acetate) and vitamin $\mathrm{C}$ (ascorbic acid). The guaranteed analysis panel on the packaging gave the following information: protein, $\min 20 \%$; fat, $\min 7 \%$; fiber, $\max 6 \%$; ash, $\max$ $6 \%$; $\mathrm{Ca}$, min $1.2 \%$ and $\mathrm{P}$, min $1 \%$.

The commercial extruded dog food was ground, water was added to the meal and in a pelleting machine the porridge was pressed through a die at environmental temperature. The food pellets obtained were sundried. The experimental diets consisted of the homogenized dry food, mixed with either 2,4 or $8 \%$ polydextrose and were then pelleted as described for the control diet. The control diet did not contain polydextrose, but it was also homogenized, pelleted and sundried. For the preparation of the control and experimental diets, the commercial diet used was derived from the one production batch.

Measurements: Feed intake was recorded at 5 and 30 min after the supply of food. At the beginning of each period, body weights of the dogs were determined.

During the last 5 days of each period, the dogs were confined individually in their own cages. Feces quality was scored on a 1-5 scale (Waltham Faecal Grading System) and feces were collected quantitatively per dog. Immediately after feces collection, fecal odor was scored by the same person. The odor was scored on a 1-5 scale with 1 being the least offensive and 5 the most offensive. The scale was based on a reference range of butanol-1 solutions. The procedure for the assessment of fecal odor intensity has been described elsewhere (Lowe and Kershaw, 1997).

The feces collections per dog and per period were pooled and weighed. The $\mathrm{pH}$ of the pooled feces was measured in fecal homogenates after the addition of demineralized water in a $1: 1(\mathrm{w} / \mathrm{w})$ ratio. Feces and diet samples were analyzed for crude protein, crude fiber, ash and crude fat. Nitrogen-free extract (nonstructural carbohydrates) was calculated as residual fraction. Calcium was determined by atomic absorption spectroscopy and phosphorus was measured colorimetrically. The methods of chemical analyses have been described elsewhere (Yuangklang et al., 2004, 2010).

On the last day of each period of feces collection, the dogs were walked to collect fresh feces. One gram of feces was mixed with $0.5 \mathrm{~mL}$ glycerol and the mixture stored at-20 $\mathrm{C}$ until the analysis of the number of viable Lactobacilli as described (Yuangklang et al., 2010).

Statistical analysis: The data were subjected to ANOVA and the dose effect of polydextrose was tested for linearity with the use of the SPSS/PC+ computer 
program. The level of statistical significance was preset at $\mathrm{p}<0.05$.

\section{RESULTS}

The analyzed composition of the diets is shown in Table 1. The dry matter contents of the four diets were similar. The inclusion of increasing amounts of polydextrose in the experimental diets at the expense of the same amount of control diet caused decreasing levels of protein, fat and calcium, but increasing levels of crude fiber and nitrogen-free extract.

The amount of food supplied per day per dog ranged from 601-640 $\mathrm{g}$ for the males and 502-532 for the females. There was no effect of the amount of polydextrose on food acceptance. There were no food leftovers. Most dogs consumed their meals within 5 min and all dogs did so within 30 min. Body weights of the dogs were not significantly influenced by the level of polydextrose in the diet. Initial body weights ranged from to $21.5-32.0 \mathrm{~kg}$ and weight changes during each dietary period were less than $0.7 \mathrm{~kg}$.

The addition of up to $8 \%$ polydextrose to the diet did not influence the amount of feces when expressed either as total weight or as dry matter (Table 2). Increasing dietary polydextrose concentrations caused increasing scores for feces consistency; there was a statistically significant linear trend. The feces scores also differed significantly among the four treatments. Fecal odor scores were not affected by the addition of polydextrose to the diet. The observer described the fecal odor for all dietary treatments, including the control diet, as very offensive.

The apparent total digestive tract digestibilities of dry matter, crude fat and crude protein were not significantly influenced by the level of polydextrose in the diet (Table 3). There was a tendency towards a linear dose effect of polydextrose on apparent crude protein digestibility. The apparent digestibility of the nitrogen-free extract was raised by polydextrose in a significant, linear fashion, but the digestibility for the diet with $2 \%$ polydextrose was aberrant. Apparent digestibility of crude fiber was raised by the addition of polydextrose to the diet. The highest group-mean value for fiber digestibility was seen when the diet containing $4 \%$ polydextrose was fed. Group-mean apparent ash digestibilities were markedly higher when the dogs were the fed the diets with 4 or $8 \%$ polydextrose instead of the control diet or the diet with $2 \%$ polydextrose, but the differences were not statistically significant.

Group-mean apparent calcium absorption was lower for the diets containing polydextrose than for the control diet, but the difference was not statistically significant and there was no dose effect (Table 4). Apparent absorption of phosphorus was not systematically influenced by polydextrose consumption.

Table 1: Ingredients and analysed composition of the experimental diets

\begin{tabular}{|c|c|c|c|c|}
\hline & \multicolumn{4}{|c|}{ Polydextrose (\%) } \\
\hline & 0 & 2 & 4 & 8 \\
\hline Ingredients & & $\mathrm{g} / \mathrm{kg}$ & & \\
\hline Complete dry food & 1000.0 & 980.0 & 960.0 & 920.0 \\
\hline Polydextrose & 0.0 & 20.0 & 40.0 & 80.0 \\
\hline Chemical analysis & & $\mathrm{g} / \mathrm{kg}$ die & & \\
\hline Dry matter & 871.7 & 867.2 & 869.9 & 870.1 \\
\hline Crude fat & 75.3 & 69.1 & 68.2 & 65.7 \\
\hline Crude protein & 201.0 & 197.8 & 180.3 & 168.3 \\
\hline Crude fiber & 59.7 & 65.6 & 75.8 & 76.7 \\
\hline Ash & 100.9 & 101.8 & 102.9 & 102.7 \\
\hline Nitrogen-free extract & 434.8 & 432.9 & 442.7 & 456.7 \\
\hline Calcium & 18.8 & 14.2 & 12.8 & 12.7 \\
\hline Phosphorus & 13.0 & 11.9 & 12.8 & 11.3 \\
\hline
\end{tabular}

Table 2: Production, consistency and odor of feces produced by the dogs fed the experimental diets

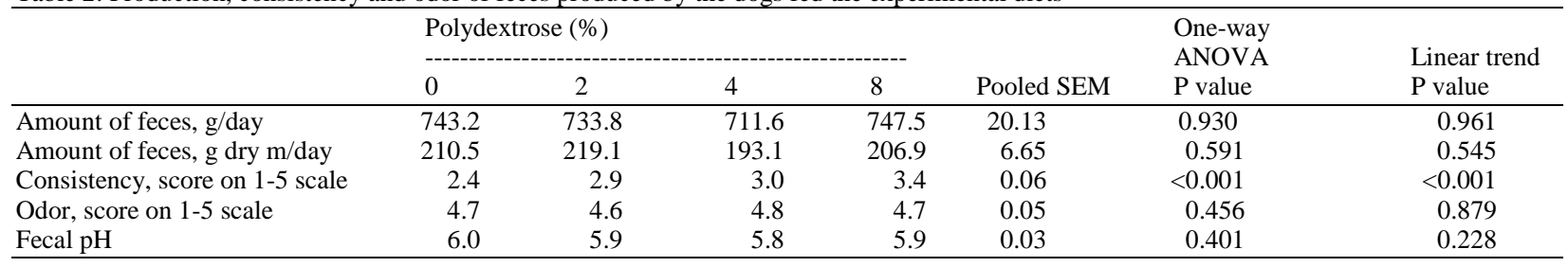

Table 3: Apparent digestibility of macronutrients in the dogs fed the experimental diets

\begin{tabular}{|c|c|c|c|c|c|c|c|}
\hline & \multicolumn{4}{|c|}{ Polydextrose $(\%)$} & \multirow[b]{2}{*}{ Pooled SEM } & \multirow{2}{*}{$\begin{array}{l}\text { One-way ANOVA } \\
\mathrm{P} \text { value }\end{array}$} & \multirow{2}{*}{$\begin{array}{l}\text { Linear trend } \\
\mathrm{P} \text { value }\end{array}$} \\
\hline & 0 & 2 & 4 & 8 & & & \\
\hline \multicolumn{8}{|l|}{ Apparent digestibility, \% of intake } \\
\hline Dry matter & 63.0 & 62.0 & 67.1 & 65.7 & 1.08 & 0.313 & 0.170 \\
\hline Crude fat & 79.2 & 79.8 & 82.3 & 80.4 & 1.28 & 0.855 & 0.615 \\
\hline Crude protein & 71.6 & 68.4 & 69.2 & 65.3 & 1.10 & 0.250 & 0.072 \\
\hline Crude fiber & 6.6 & 14.3 & 30.3 & 24.5 & 3.13 & 0.031 & 0.011 \\
\hline Ash & 10.2 & 8.1 & 21.0 & 18.3 & 2.87 & 0.327 & 0.153 \\
\hline Nitrogen-free extract & 67.3 & 63.6 & 71.3 & 72.1 & 1.17 & 0.032 & 0.029 \\
\hline
\end{tabular}


American J. Animal \& Vet. Sci., 6 (3): 105-111, 2011

Table 4: Apparent absorption of calcium and phosphorus by the dogs fed the experimental diets

\begin{tabular}{|c|c|c|c|c|c|c|c|}
\hline & \multicolumn{4}{|c|}{ Polydextrose (\%) } & \multirow[b]{2}{*}{ Pooled SEM } & \multirow{2}{*}{$\begin{array}{l}\text { One-way } \\
\text { ANOVA } \\
\mathrm{P} \text { value }\end{array}$} & \multirow{2}{*}{$\begin{array}{l}\text { Linear trend } \\
\mathrm{P} \text { value }\end{array}$} \\
\hline & 0 & 2 & 4 & 8 & & & \\
\hline \multicolumn{8}{|c|}{ Apparent mineral absorption, $\%$ of intake } \\
\hline Calcium & 29.2 & 16.0 & 14.8 & 14.9 & 4.96 & 0.693 & 0.330 \\
\hline Phosphorus & 14.3 & 12.1 & 18.6 & 8.4 & 5.38 & 0.930 & 0.825 \\
\hline
\end{tabular}

The intake of polydextrose did not alter the number of viable Lactobacilli in feces. The average numbers were $8.29,8.20,8.25$ and $8.22 \log 10 / \mathrm{g}$ wet weight of feces for the control diet and the diets with increasing levels of polydextrose, respectively.

\section{DISCUSSION}

STA-LITE $^{\circledR}$ polydextrose is a pure, soluble fibre that is synthesized from dextrose. It is a highly branched glucose polymer containing different glycosidic bonds with $\alpha-1,6$ bonds predominating. The STA-LITE $^{\circledR}$ polydextrose preparation contains $90 \%$ polydextrose, the remaining $10 \%$ having constituents such as moisture, dextrose and sorbitol. For the determination of polydextrose in foods, a specific analytical method (AOAC 2000.11) should be used. The classical methods for proximate feed analyses are inappropriate because a small portion of the soluble polydextrose fiber will be recovered by crude fiber analysis which mainly detects insoluble fibers. As a consequence, a significant portion of polydextrose will be assigned to the so-called nitrogen-free extract. The addition of $8 \%$ polydextrose to the commercial dog food raised the crude fiber content from 6.0-7.7 \% and the nitrogen-free extract fraction from $43.5-45.7 \%$. It can be calculated that $28 \%$ of the polydextrose was present in the crude fiber fraction and $72 \%$ in the nitrogen-free extract. The total recovery of the added polydextrose was $99 \%$ for the diet with $8 \%$ polydextrose. As would be expected, the addition of polydextrose to the commercial dog food lowered the concentrations of fat and protein in the final mixture. The addition of $8 \%$ polydextrose to the commercial dog food lowered the fat and protein level from 7.5-6.6 and from $20.1-16.8 \%$, respectively.

The dietary inclusion of polydextrose up to a level of $8 \%$ did not affect food acceptance and body weight. It should be stressed that each dog was fed an amount of food that was equivalent to its habitual daily intake of energy, thus allowing body weight maintenance. To calculate the energy value of the experimental diets, the energy value for polydextrose was assumed to be $4 \mathrm{~kJ}$ per $\mathrm{g}$ (Auerbach et al., 2007). Given the fact that body weights did not systematically change during the course of the experiment, it may be concluded that the energy contents of the habitual and experimental diets had been assessed properly.

The ingestion of polydextrose did neither affect fresh feces output nor the production of fecal dry matter. This indicates that polydextrose feeding had no impact on the total water content of feces. Indeed, the fraction of fecal water for the control diet was on average $29.0 \%$, whereas it was $27.9 \%$ for the diet containing $8 \%$ polydextrose. The addition of polydextrose to the diet raised the mean fecal score from 2.4 to 3.4 in a dose-dependent fashion. According to the scoring system, a score of 2.4 corresponds with the description of well formed feces with a slightly moist surface, leaving a mark when picked up. A score of 3.4 is equivalent with very moist feces, but still having some definite form. This feces might have contained more free water rather than total water. High inclusion levels of polydextrose may have adverse effects on feces consistency. The feeding of diets containing $10 \%$ polydextrose to dogs has been shown to cause overt diarrhea (Knapp et al., 2008). In this study, no influence of the amount of polydextrose in the diet on fecal odor could be detected, indicating that polydextrose may not induce the formation of putrefactants.

Based on the feces scores found in this study, we decided to use an inclusion level of 3\% polydextrose in our clinical trial with privately owned dogs with osteoarthritis (Beynen et al., 2011). It was anticipated that $3 \%$ polydextrose in the diet would produce an average fecal score of about 3.0, which is described as moist feces, beginning to lose form and leaving a definite mark when picked up. The dog owners were asked to score feces quality on a scale from dry and hard $(0)$ to thin and watery (100). After the 8-weeks feeding period, the average feces score for the 16 dogs fed the control diet was 51.4 and for the 19 dogs given the polydextrose-containing diet it was 54.1, the difference not being significant. Thus, both the controlled experiment and the field trial indicate that the addition of $3 \%$ polydextrose to dog food will lead to the production of feces with acceptable consistency.

With the use of the observed group-mean apparent digestibilities of crude fiber and nitrogen-free extract for the control diet and the diet with $8 \%$ polydextrose, the apparent digestibility of polydextrose was calculated. The portion of polydextrose recovered in the 
crude fiber fraction had a digestibility of $70 \%$ and for that present in the nitrogen-free extract it was $100 \%$. Thus, the apparent digestibility of the polydextrose preparation used was calculated to be $92 \%$ of the intake. The apparent digestibility reflects the sum of digestion in the small intestine and fermentation of nondigested polydextrose in the large intestine. Because of its atypical linkages between glucose moieties, polydextrose largely resists digestion by mammalian gastrointestinal digestive enzymes. Minimal amounts of polydextrose are absorbed in the small intestine, explaining the low glycemic response after polydextrose intake (Foster-Powell et al., 2002) and its low caloric value (Auerbach et al., 2007). In rats, ingested polydextrose is extensively fermented in the large intestine, leading to the production of short-chain fatty acids (Weaver et al., 2010). In the colon of the dogs, there probably was selective fermentation because polydextrose intake did not lower fecal $\mathrm{pH}$. This may relate to the fact that the fecal $\mathrm{pH}$ for the control diet was 6.0, which may be considered low (Beynen et al., 2001). Feeding of the non-digestible, highly fermentable lactulose lowered fecal $\mathrm{pH}$ values in dogs from 7.1-6.6 (Beynen et al., 2001). In humans, as much as approximately $50 \%$ of the ingested dose may be excreted as such with the feces (Aucherbach et al., 2007; Charalampopoulos and Rastall, 2009). This may does not hold for dogs as indicated by the high apparent digestibility of polydextrose.

When the dogs were fed diets containing up to $8 \%$ polydextrose, the number of viable Lactobacilli in feces remained unchanged. Until now, the conducted research in humans has not yielded consistent information on the prebiotic activity of polydextrose. This probably relates to differences in experimental conditions, including the dose used and confounding factors. Prebiotic activity of polydextrose has been demonstrated in some studies (Jie et al., 2000; Tiihonen et al., 2008), whereas in other studies only a trend or no effect was found (Hengst et al., 2009; Boler et al., 2011). Jie et al. (2000) showed a dose-dependent increase in Lactobacilli and Bifidobacteria while the numbers of non-beneficial bacteria fell. In another study human subjects were fed a high-cholesterol diet without or with $15 \mathrm{~g}$ of supplemental polydextrose for two weeks. The intake of polydextrose did not change the number of fecal Bifidobacteria, but it significantly reduced Clostridium perfringens, which is considered an undesirable colonic micro-organism.

Polydextrose is a soluble, but not a viscous fiber. This explains that increasing intakes of polydextrose did not affect apparent fat digestibility by the dogs. The intake of high amounts of viscous fiber by monogastric animals raises the viscosity of the intestinal digesta and depresses fat digestion, possibly through reducing the availability of bile acids for the formation of micelles (Smits et al., 1998). This phenomenon may also hold for dogs. Fahey et al. (1990) reported that increasing levels of beet pulp up to $12.5 \%$ in a dry dog food cause a dose-dependent decrease in apparent fat digestibility. Beet pulp contains about $20 \%$ of the viscous, gelforming fiber pectin, which explains its effect on fat digestibility. Thus, unlike pectin, polydextrose does not interfere with fat digestion.

Apparent crude protein digestibility was measured as total nitrogen intake minus total fecal nitrogen excretion and is expressed as a percentage of intake. Polydextrose consumption did not significantly affect apparent crude protein digestibility in the dogs, but there was a tendency towards a dose-dependent lowering. This observation reflects an indirect, artificial effect rather than true inhibition of protein digestion. First, there is no molecular basis for any effect of polydextrose on the process of protein digestion in the stomach and small intestine. Secondly, the formulation of the experimental diets by mixing polydextrose into a complete dog food caused decreasing dietary protein concentrations with increasing inclusion levels of polydextrose. A decrease in protein intake by itself will lead to a lower value for apparent protein digestibility because the endogenous fecal nitrogen excretion becomes a larger fraction of total fecal nitrogen. Thirdly, the polydextrose-induced increase in colonic fermentation and bacterial growth (Weaver et al., 2010) raises fecal excretion of bacterial nitrogen, which will lower apparent total gastro-intestinal tract digestibility of crude protein. It is concluded that polydextrose feeding does not influence true protein digestibility.

Increasing intakes of polydextrose by the dogs did not systematically and not significantly affect apparent absorption of ash, calcium and phosphorus absorption. Likewise, Weaver et al. (2010) observed that the feeding of a diet containing polydextrose to rats did not enhance calcium absorption. It appears that polydextrose does not influence the solubility of minerals in the small intestinal digesta. The efficiency of mineral absorption is controlled by the solubility of minerals in the soluble fraction of ileal contents, which in turn is determined by the $\mathrm{pH}$ of ileal digesta (Heijnen et al., 1993). It may be suggested that there is no fermentation of ingested polydextrose in the small intestinal lumen so that the $\mathrm{pH}$ of the digesta is not lowered. In rats, the consumption of non-digestible, highly fermentable carbohydrates, such as lactose and lactulose, lower $\mathrm{pH}$ values and raise the solubility of minerals in the ileal digesta (Heijnen et al., 1993). 


\section{CONCLUSION}

In the present dose-response study with Latinsquare design, healthy dogs were fed a commercial dry food to which either $0,2,4$ or $8 \%$ polydextrose was added. At the various inclusion levels, polydextrose did not affect the acceptance of food, food intake and body weight. The amount feces produced and fecal odor were not influenced by polydextrose intake. Feces consistency was significantly affected by polydextrose; feces became softer with increasing dose. It is concluded that an inclusion level of 3\% polydextrose induces acceptable feces consistency. Polydextrose in the diet did not significantly affect the apparent digestibility of dietary dry matter, crude fat, crude protein and ash. The apparent digestibility of crude fiber and nitrogen-free extract were increased. The apparent digestibility of polydextrose was calculated to be $92 \%$. The lack of effect of polydextrose feeding on fecal $\mathrm{pH}$ and Lactobacilli might point at selective fermentation of this functional ingredient in the hindgut of dogs.

We have provided evidence that polydextrose at a dose of 3\% in a dry food may diminish the clinical signs in dogs with osteoarthritis (Beynen et al., 2011). This study indicates that $3 \%$ polydextrose does not have negative effects in dogs, which would support application of polydextrose as a functional ingredient in dog food.

\section{ACKNOWLEDGEMENT}

This study was funded by Tate and Lyle. The research and all publications arising out of or referable to it are considered proprietary data to which Tate and Lyle claims exclusive right of reference in accordance with Regulation (EC) no 1924/2006 of the European Parliament and of the Council on Nutrition and Health Claims Made on Foods.

\section{REFERENCES}

Auerbach, M.H., S.A.S. Craig, J.F. Howlett and K.C. Hayes, 2007. Caloric availability of polydextrose. Nutr. Rev., 65: 544-549. DOI: 10.1111/j.17534887.2007.tb00279.x

Beynen, A.C., D.H.J. Saris, L.D. Jong, M. Staats and A.W.C. Einerhand, 2011. Impact of dietary polydextrose on clinical signs of canine osteoarthritis in a double-blind, placebo-controlled trial. Am. J. Anim. Vet. Sci., 6: 93-99. DOI: 10.3844/ajavsp.2011.93.99
Beynen, A.C., H.J. Kappert and S. Yu, 2001. Dietary lactulose decreases apparent nitrogen absorption and increases apparent calcium and magnesium absorption in healthy dogs. J. Anim. Physiol. Anim. Nutr., 85: 67-72. PMID: 1168774 DOI: 10.1046/j.1439-0396.2001.00301.x

Boler, B.M.V., M.C.R. Serao, L.L. Bauer, M.A. Staeger and T.W. Boileau et al., 2011. Digestive physiological outcomes related to polydextrose and soluble maize fiber consumption by healthy adult men. Br. J. Nutr., 31: 1-8. PMID: 21736814

Charalampopoulos, D. and R.A. Rastall, 2009. Prebiotics and Probiotics Science and Technology. 1st Edn., Springer, New York, ISBN: 0387790578, pp: 1265 .

Fahey, G.C., Jr., N.R. Merchen, J.E. Corbin, A.K. Hamilton and K.A. Serbe et al., 1990. Dietary fiber for dogs: I. Effects of graded levels of dietary beet pulp on nutrient intake, digestibility, metabolizable energy and digesta mean retention time. J. Anim. Sci., 68: 4221-4228. PMID: 1962765

Fava, F., H. Makivuokko, H. Siljander-Rasi, H. Putaala and K. Tiihonen et al., 2007. Effect of polydextrose on intestinal microbes and immune functions in pigs. Br. J. Nutr., 98: 123-133. DOI: 10.1017/S0007114507691818 PMID: 17391567

Foster-Powell, K., S.H. Holt and J.C. Brand-Miller, 2002. International table of glycemic index and glycemic load values: 2002. Am. J. Clin. Nutr., 76: 5-56. PMID: 12081815

Heijnen, A.M.P., E.J. Brink, A.G. Lemmens and A.C. Beynen, 1993. Ileal $\mathrm{pH}$ and apparent absorption of magnesium in rats fed on diets containing either lactose or lactulose. Br. J. Nutr., 70: 747-756. PMID: 8297913 DOI: 10.1079/BJN19930170

Hengst, C., S. Ptok, A. Roessler, A. Fechner and G. Jahreis, 2009. Effects of polydextrose supplementation on different faecal parameters in healthy volunteers. Int. J. Food Sci. Nutr., 60: 96105. PMID: 19107626

Henrotin, Y., C. Sanchez and M. Balligand, 2005. Pharmaceutical and nutraceutical management of canine osteoarthritis: Present and future perspectives. Vet. J., 170: 113-123. DOI: 10.1016/j.tvj1.2004.08.014 PMID: 15993795

Jie, Z., L. Bang-Yao, X. Ming-Jie, L. Hai-Wei and Z. Zu-Kang et al., 2000. Studies on the effects of polydextrose intake on physiologic functions in Chinese people. Am. J. Clin. Nutr., 72: 1503-1509. PMID: 11101478 
Knapp, B.K., C.M. Parsons, K.S. Swanson and G.C. Fahey, Jr., 2008. Physiological responses to novel carbohydrates as assessed using canine and avian models. J. Agric. Food Chem., 56: 7999-8006. DOI: 10.1021/jf801042b PMID: 18707118

Lowe, J.A. and S.J. Kershaw, 1997. The ameliorating effect of Yucca schidigera extract on canine and feline faecal aroma. Res. Vet. Sci., 63: 61-66. PMID: $\quad 9368958$ DOI: $10.1016 /$ S00345288(97)90159-4

Makivuokko, H., J. Nurmi, P. Nurminen, J. Stowell and N. Rautonen, 2005. In vitro effects on polydextrose by colonic bacteria and caco-2 cell cyclooxygenase gene expression. Nutr. Cancer, 52: 94-104. DOI: 10.1207/s15327914nc5201_12 PMID: 16091009

Peuranen, S., K. Tiihonen, J. Apajalathi, A. Kettunen and M. Saarinen et al., 2004. Combination of polydextrose and lactitol affects microbial ecosystem and immune responses in rat gastrointestinal tract. Br. J. Nutr., 91: 905-914. DOI: 10.1079/BJN20041114 PMID: 15182394

Smits, C.H., A. Veldman, H.J. Verkade and A.C. Beynen, 1998. The inhibitory effect of carboxymethylcellulose with high viscosity on lipid absorption in broiler chickens coincides with reduced bile salt concentration and raised microbial numbers in the small intestine. Poult. Sci., 77: 1534-1539. PMID: 9776062
Tiihonen, K., T. Suomalainen, S. Tynkkynen and N. Rautonen, 2008. Effect of prebiotic supplementation on a probiotic bacteria mixture: Comparison between a rat model and clinical trials. Br. J. Nutr., 99: 826-831. PMID: 17868490 DOI: 10.1017/S0007114507825141

Weaver, C.M., B.R. Martin, J.A. Story, I. Hutchinson and L. Sanders. 2010. Novel fibers increase bone calcium content and strength beyond efficiency of large intestine fermentation. J. Agric. Food Chem. PMID: 20677817

Yuangklang, C., T. Wensing, L.V.D. Broek, S. Jittakhot and A.C. Beynen, 2004. Fat digestion in veal calves fed milk replacers low or high in calcium and containing either casein or soy protein isolate. J. Dairy Sci., 87: 1051-1056. PMID: 15259241 DOI: $10.3168 /$ jds.S0022-0302(04)73251-8

Yuangklang, C., C. Wachirapakorn, H.E. Mohamed, A. Alhaidary and A.C. Beynen et al., 2010. Effect of calcium supplementation on growth, nutrient digestibility and fecal lactobacilli in dairy calves. Am. J. Anim. Vet. Sci., 5: 127-131. DOI: 10.3844/ajavsp.2010.127.131 